\title{
Partenariat Santé: Results of a Community Program to Improve the Cardiovascular Health among Adult Population
}

\author{
Jean-François Giguère ${ }^{1,2}$, Pauline Brayet ${ }^{3}$, Camille Genest ${ }^{3}$, Alexis Mercier ${ }^{1}$, William Leblanc ${ }^{1}$, \\ Maria-Cécilia Gallani ${ }^{1,2}$
}

${ }^{1}$ Faculty of Nursing, Université Laval, Quebec, Canada

${ }^{2}$ Québec Heart and Lung Institute, Quebec, Canada

${ }^{3}$ Faculty of Medicine, Université Laval, Quebec, Canada

Email: jean-francois.giguere@fsi.ulaval.ca

How to cite this paper: Giguère, J.-F., Brayet, P., Genest, C., Mercier, A., Leblanc, W. and Gallani, M.-C. (2021) Partenariat Santé: Results of a Community Program to Improve the Cardiovascular Health among Adult Population. Open Journal of Preventive Medicine, 11, 147-158.

https://doi.org/10.4236/ojpm.2021.114012

Received: March 20, 2021

Accepted: April 26, 2021

Published: April 29, 2021

Copyright $\odot 2021$ by author(s) and Scientific Research Publishing Inc. This work is licensed under the Creative Commons Attribution International License (CC BY 4.0).

http://creativecommons.org/licenses/by/4.0/

(c) (i) Open Access

\begin{abstract}
Partenariat Santé (PS) launched in Québec in 2016, is inspired from the Cardiovascular Health Awareness Program (CHAP) and consists of a free session held in the community by students coming from different health sciences programs. The program's mission is to make available early detection of modifiable CVD risk factors, raise awareness of participants about their impact on CVDs, and promote healthy life changes. In order to gather information to optimize the implementation of this program and eventually to enlarge its implementation to other sites, the first objective of this study was to explore the characteristics of the adult population participating in the PS program and to identify the risk factors they want to modify. The second objective was to evaluate one month later the effective implementation of the action plan elaborated during the motivational interview. The third objective was to evaluate the satisfaction of the participants with the PS program. One hundred ten subjects who attended PS sessions during this period were enrolled in the study. About $30 \%$ of participants have blood pressure values $\geq$ $140 / 90 \mathrm{mmHg}$ and $40 \%$ present a waist circumference associated with higher risk profile. The behaviors to be changed mostly targeted by the participants were physical inactivity and nutrition. A motivational interview was conducted with the elaboration of an action plan to support the behavioral/outcomes changes. Sixty participants (54.5\%) completed the questionnaire in the one-month follow-up. Forty-one (68.3\%) participants revealed that they had put their action plans into practice, while $63.3 \%$ claimed that they mostly reached their objectives. Motivation remains high after one month for participants who put their action plans in place $(7.8 \pm 1.9$ versus $7.4 \pm 1.6$; $\mathrm{p}=$
\end{abstract}


0.214), whereas it decreased significantly for those who did not $(6.8 \pm 2.1$ versus $5.8 \pm 2.0 ; \mathrm{p}=0.029)$. The majority of them agreed that PS program was useful $(75 \%)$ and led them to change their lifestyle related to cardiovascular health $(62 \%)$. In conclusion, our results suggest that the PS program can produce benefits on the promotion of cardiovascular health in the community adult population, being evaluated as useful to change the lifestyle related to CVD risk.

\section{Keywords}

Community Health, Motivational Interview, Lifestyle Management, Health Promotion

\section{Introduction}

Cardiovascular diseases (CVDs) are the leading cause of death in the world. They were responsible for 17.9 million deaths in 2016, representing $31 \%$ of worldwide deaths [1]. In Canada, CVDs also represent a heavy burden for health-care systems. They generated nearly $\$ 21$ billion in direct and indirect costs in 2005 [2]. Moreover, nine Canadians out of 10 over the age of 20 years have at least one risk factor for developing CVDs, and two out of five have three or more [3]. A risk factor is a characteristic of an individual that is associated with an increased risk of developing a disease. Non-modifiable risk factors of CVDs include age, gender, ethnicity, socioeconomic status, diabetes, genetic susceptibility and family history of CVDs. Modifiable risk factors comprise sedentary lifestyle, smoking, excessive alcohol consumption, insufficient intake of fruit and vegetables, excessive intake of salt, fat, and sugar, blood lipid profile, obesity or overweight, and high blood pressure. The World Health Organisation estimates that three-quarters of CVDs could be prevented [1]. Hence, providing early detection of these modifiable risk factors and addressing them, along with raising public awareness, could decrease the epidemic of CVDs and its health and economical impacts.

The understanding of the importance of enlarging the offer of prevention actions to the overall population gave rise to community initiatives such as the Cardiovascular Health Awareness Program (CHAP), which was developed and implemented in Ontario [4]. This program provides free risk assessment and information sessions that are held in places where people work, live and gather, as pharmacies, community health centers, primary care practices, places of worship, shopping centers, workplaces, community events, service group facilities, or other easily accessible locations [4] [5]. This program aims to prevent CVDs through blood pressure measurements, promotion and teaching of healthy lifestyles, and referral to community resources. This initiative has been adapted to different settings and populations, including older adults [6] [7], low and middle-income countries [8] [9], individuals waiting for a family physician [10], as 
well as hospital employees [11], with promising results. Indeed, in older adults population, CHAP has led to a9\% decrease in the hospitalisation rates for cardiovascular-related causes among participants aged 65 years and older [7] and this benefit effect persisted in the first five years [12]. Moreover, participants who attended three CHAP sessions and who were monitored for 18 months recorded a mean reduction of $19 \mathrm{mmHg}$ in systolic blood pressure [13]. In a systematic review aimed at assessing the effectiveness of community programs for the prevention of CVDs, and defined as those targeting multiple CVD risk factors in the whole population living within a certain geographic area, Pennant et al. (2010) reported an average net reduction in 10-year CVD risk of 0.65\% [14].

These data inspired the implementation of Partenariat Santé(PS) in 2016. The program's mission is to make available to the adult population of the province of Quebec in Canada the early detection of modifiable risk factors for CVDs, raise awareness about their impact on CVDs, and promote healthy life changes through free sessions held in the community by voluntary students coming from different programs in health-sciences at Université Laval [15].

In order to gather information to optimize and consolidate the implementation of this program and eventually to enlarge its implementation to other sites, the first objective of this study was to explore the characteristics of the adult population participating in the PS program and to identify the risk factors they want to modify. The second objective was to evaluate one month later the effective implementation of the action plan elaborated during the motivational interview. The third objective was to evaluate the satisfaction of the participants with the PS program.

\section{Methods}

\subsection{Setting and Participants}

Participants were recruited among individuals who attended the PS program between February and December 2019. During this period, eight sessions were held in Québec, including three in public spaces, four in workplace environments and one in a community sports centre. Posters, emails, and social media publicized the program before the sessions were held. For the sessions in community settings, recruitment consisted of inviting the general public to participate. Recruitment for workplace sessions was done beforehand. Employees interested in participating in the PS program had to schedule an appointment online, on a Doodle send by email by their employer. This information was then transmitted to the PS coordinator responsible for the session and appointments were made with the interested employees. Participants who have identified a risk factor that needs to be changed and have a plan to change it as well as who agree to be contacted one month later were recruited in this study.

\subsection{Study Procedure}

Figure 1 represents a schematic representation of experimental setups. The PS 
PS session - in person $(n=110)$

- Questionnaire on CVD risk factors

- Blood pressure and waist circumference measurment

Motivational interviewing, including action plan

formulation and level of motivation to implement it

- Referencing to appropriate community resources

- Invitation for the 1 month follow-up survey

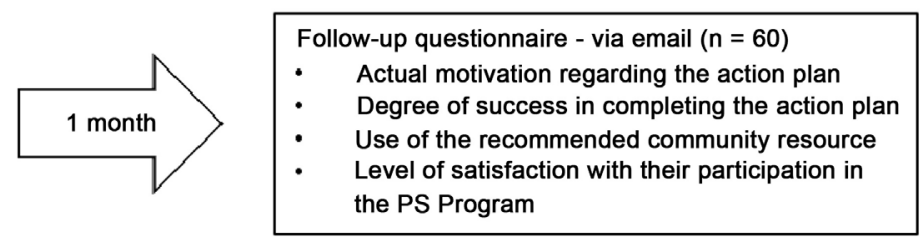

Figure 1. Schematic representation of experimental setups.

sessions consisted of three successive steps. Firstly, the participants responded to a questionnaire on CVD risk factors (smoking, drinking, eating and exercise habits) they would like to change. Secondly, a trained volunteer (a student in a health-science program at Université Laval) measured the participants' waist circumference and blood pressure, using an automated device, according to the Canadian Guidelines [16] [17]. Participants with blood pressure $>170 / 110 \mathrm{mmHg}$ were referred to a health professional. Thirdly, the participants met with another student volunteer for an individual interview who applied the principles of motivational interviewing to enhance the motivation of the participant to modify the risk factor targeted in the first step. The motivational interviewing strategy is a counselling method aimed at increasing motivation through the resolution of ambivalence. The questions guiding the session respect three great assumptions: the importance of change for the patient (willingness), the confidence to change (ability) and whether change is an immediate priority (readiness) [18]. At the end of the session, an action plan to modify the risk factor was elaborated and level of motivation to implement this action plan was documented (Likert type scale; $0=$ not at all motivated and $10=$ extremely motivated). Participants were also referred to appropriate community resources that could be useful to support the action plan.

At the end of the session, participants were asked about their interest to have a follow-up 1 month later. If they accept the follow-up was intended to evaluate the adherence of the participant to the action plan elaborated during the PS session as well as the satisfaction with their participation in the program. For those accepting to participate, a questionnaire containing seven open and ended questions was sent to them via email using the RedCap software. The follow-up was intended to evaluate the adherence of the participant to the action plan elaborated during the PS session, as well as the satisfaction with their participation in the program. This questionnaire included actual motivation regarding the action plan (Likert type scale; $0=$ not at all motivated and $10=$ extremely motivated), degree of success in completing the action plan, as well as open-ended questions to identify the reason for the abandon of the action plan, if applied, and about the use of the recommended community resource and its utility for the modification of the risk factor. Finally, the participants were asked to score their level of satisfaction with their participation in the PS program (Likert type scale; $1=$ strongly disagree and $6=$ strongly agree) and to provide suggestions to optimize the program. 


\subsection{Statistical Analysis}

All data obtained were entered in a database created in the RedCap international database and transferred to SPSS, version 26.0, for descriptive and inferential analysis. Means and standard deviations were calculated for continuous variables, and percentages were calculated for categorical variables. To compare continuous variables, t-tests were used for normally distributed variables (age, waist circumference and blood pressure) and non-parametric tests were used for the nonnormally distributed variable, i.e., motivation level (Wilcoxon signed-rank and $\mathrm{U}$ Mann-Whitney). Chi-square was used to compare categorical variables.

\subsection{Ethical Aspects}

The study protocol was explained to all the participants before signing the consent form. Participation was voluntary and no compensation was offered. The study and consent procedures were approved by the local research ethics committee (approved February 15, 2019, number 2019-3176, 21727).

\section{Results}

\subsection{Sociodemographic and Clinical Characteristics of Participants}

One hundred and ten participants agreed to participate in this research project (67 women; mean age $47.2 \pm 13.6$ years) (Table 1 ), being 39 recruited in the three public spaces, 67 from the four workplace environments and 18 from the community sports centre. No statistical difference was found for age between sexes (46.2 \pm 15.7 for men and $47.9 \pm 12.1$ for women). Waist circumference was $\geq 102 \mathrm{~cm}$ for $25.6 \%$ of men $(\mathrm{n}=11)$ and $\geq 88 \mathrm{~cm}$ for $49.3 \%$ of women $(\mathrm{n}=33)$. Blood

Table 1. Sociodemographic and clinical characteristics of subjects.

\begin{tabular}{|c|c|c|c|c|}
\hline & $\begin{array}{l}\text { Total Sample } \\
\quad(\mathrm{N}=110)\end{array}$ & $\begin{array}{c}\text { Men } \\
(\mathrm{N}=43)\end{array}$ & $\begin{array}{l}\text { Women } \\
(\mathrm{N}=67)\end{array}$ & \multirow[t]{2}{*}{$P$ value } \\
\hline & Mean \pm SD & Mean \pm SD & Mean \pm SD & \\
\hline Age (years) & $\begin{array}{c}47.2 \pm 13.6 \\
(19-77)\end{array}$ & $\begin{array}{c}46.2 \pm 15.7 \\
(19-77)\end{array}$ & $\begin{array}{c}47.9 \pm 12.1 \\
(26-74)\end{array}$ & NS \\
\hline $\mathrm{SBP}(\mathrm{mmHg})$ & $\begin{array}{c}129 \pm 16 \\
(58-112)\end{array}$ & $\begin{array}{c}135 \pm 14 \\
(104-172)\end{array}$ & $\begin{array}{c}125 \pm 15 \\
(95-161)\end{array}$ & $0.001^{\star}$ \\
\hline $\mathrm{DBP}(\mathrm{mmHg})$ & $\begin{array}{c}81 \pm 10 \\
(58-112)\end{array}$ & $\begin{array}{c}85 \pm 10 \\
(69-112)\end{array}$ & $\begin{array}{l}79 \pm 10 \\
(58-97)\end{array}$ & $0.003^{*}$ \\
\hline $\mathrm{WC}(\mathrm{cm})$ & $\begin{array}{c}92 \pm 17 \\
(61-182)\end{array}$ & $\begin{array}{c}97 \pm 19 \\
(75-182)\end{array}$ & $\begin{array}{c}89 \pm 15 \\
(61-135)\end{array}$ & $0.011^{\star}$ \\
\hline & & $\mathrm{N}(\%)$ & $\mathrm{N}(\%)$ & \\
\hline $\mathrm{WC}(\mathrm{cm})$ & & $\begin{array}{l}<102 \mathrm{~cm}: 32(74.4 \%) \\
\geq 102 \mathrm{cm:} 11(25.6 \%)\end{array}$ & $\begin{array}{l}<88 \mathrm{~cm}: 34(50.7 \%) \\
\geq 88 \mathrm{~cm}: 33(49.3 \%)\end{array}$ & $0.011^{\star *}$ \\
\hline
\end{tabular}

SBP: systolic blood pressure, DBP: diastolic blood pressure, WC: waist circumference, SD: standard deviation. ${ }^{*}$ t-Test; ${ }^{* *}$ chi-square. 
pressure measured during the PS session was $129 / 81 \pm 16 / 10 \mathrm{mmHg}$, with men recording both higher systolic $(135 \pm 14 \mathrm{mmHg}$ versus $125 \pm 15 \mathrm{mmHg} ; \mathrm{p}=$ $0.001)$ and diastolic ( $85 \pm 10$ versus $79 \pm 10 \mathrm{mmHg} ; \mathrm{p}=0.003)$ blood pressure than women. Importantly, systolic blood pressure was $\geq 140 \mathrm{mmHg}$ for 23 participants ( 11 men and 12 women) and diastolic blood pressure was $\geq 90 \mathrm{mmHg}$ for 23 participants (14 men and 9 women). Finally, waist circumference was $\geq 102 \mathrm{~cm}$ for 11 men and $\geq 88 \mathrm{~cm}$ for 33 women.

\subsection{Risk Factors Targeted and Action Plans}

During the PS session, participants were asked to identify which CVD risk factor they wanted to work on, considering their own lifestyle (Figure 2). The two most identified risk factors were bad eating habits $(50.0 \%)$ and lack of physical activity (39.1\%). High waist circumference and high blood pressure were targeted by $10.9 \%$ and $9.1 \%$ of participants, respectively, while tobacco and alcohol consumption were identified by $5.5 \%$ and $3.6 \%$ of participants, respectively. Few participants have not identified any risk factor during the session (5.5\%). Note that the percentages adding up to over $100 \%$ are due to the fact that 21 participants chose two or three risk factors.

Participants developed different action plans to modify targeted risk factors (see Table 2). These action plans were divided into two large categories - plans directly related to behavioural change and plans related to an outcome. Among the behavioral plans, those related to physical activity and nutrition were far more prevalent. Among the outcome plans, lose weight and maintain or improve health were more frequent. As for the choice of risk factors, $15.5 \%(17 / 110)$ of participants identified more than one intervention in their action plan and were thus included in more than one category.

\subsection{Implementation of Action Plan Following Partenariat Santé Session}

Among the 110 participants recruited during the PS session, sixty (54.5\%) completed the questionnaire sent one month later. Forty-one $(68.3 \%)$ of the participants completing the follow-up reported that they had put their action plans into

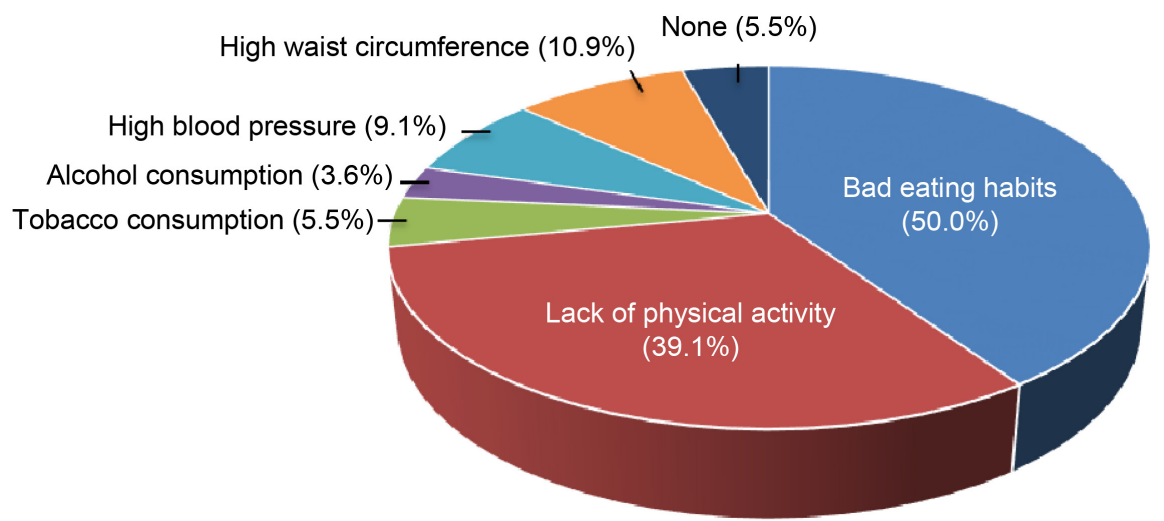

Figure 2. Cardiovascular risk factors identified by subjects. 
Table 2. Categorization and frequency of action plans.

\begin{tabular}{lc}
\hline \multicolumn{1}{c}{ Nature of action plans } & $\mathrm{N}=110$ \\
\hline Behavioral plans & 39 \\
Start, maintain or increase physical activity & 38 \\
Improve nutrition habits & $(16)$ \\
Increase fruit and vegetable consumption & $(12)$ \\
$\quad$ Eat healthier food (in general) & $(4)$ \\
Consume less sugar & $(4)$ \\
Consume less processed food or cooking at home & $(2)$ \\
Consume less fat & $(2)$ \\
Consume less salt & $(2)$ \\
$\quad$ Eat a snack/eat less snack & $(1)$ \\
Consume more water & 4 \\
Stop or reduce tobacco use & 3 \\
Stop or reduce alcohol consumption & 21 \\
Outcome plans & 11 \\
Lose weight/decrease waist circumference & 3 \\
Maintain or improve health (in general) & 2 \\
Reduce blood pressure & 21 \\
Reduce/manage stress & \\
\hline
\end{tabular}

practice, while $63.3 \%$ claimed that they mostly reached their objectives $(\geq 4$, averaging score 3.8/6). At the baseline, participant motivation to implement their action plans was high for most of the participants ( $7.5 \pm 1.9$ on a 10-point scale). As expected, for the 60 participants who completed the follow-up, motivation remained high after one month for the participants who implemented their action plans $(7.8 \pm 1.9$ versus $7.4 \pm 1.6 ; \mathrm{p}=0.214)$, whereas it decreased significantly for those who did not ( $6.8 \pm 2.1$ versus $5.8 \pm 2.0 ; \mathrm{p}=0.029)$ (Table 3$)$. Interestingly, the motivation rate during the PS session was higher among participants who put their action plans into practice than among those who did not $(7.8 \pm 1.9$ versus $6.8 \pm 2.1 ; \mathrm{p}=0.09)$, as well as one month later $(7.4 \pm 1.6$ versus $5.8 \pm 2.0 ; \mathrm{p}=0.005)$.

Finally, on a 6-point scale assessing degree of agreement, 75\% of the participants agreed that PS session was useful ( $\geq 4$, with an average score of 4.3/6) and $62 \%$ agree that the PS session drove them in the implementation of changes in their lifestyle related to cardiovascular health ( $\geq 4$, averaging score 3.5/6). As such, most participants (78.3\%) would recommend PS to friends ( $\geq 4$, averaging score 4.4/6). Only 9 subjects (15.0\%) used the community resources presented to them, but $77.7 \%$ considered that it was useful for the realization of their action plans. Lastly, 5 subjects (8.3\%) consulted a health professional, either a physician (3 subjects), a nutritionist (2 subjects), a kinesiologist (1 subject) or another health professional (1 subject). 
Table 3. Motivation among participants implementing or not their action plan.

\begin{tabular}{ccc}
\hline Implementation & \multicolumn{2}{c}{ Motivation level (on 10) } \\
\hline of action plan & During the session & One month after \\
\hline Yes $(\mathrm{n}=41)$ & $7.8 \pm 1.9^{\dagger,}$ & $7.4 \pm 1.6^{\dagger, \delta \int}$ \\
No $(\mathrm{n}=19)$ & $6.8 \pm 2.1^{+\dagger, \int}$ & $5.8 \pm 2.0^{\dagger \dagger, \int J}$ \\
\hline
\end{tabular}

${ }^{\dagger} \mathrm{NS},{ }^{\dagger \dagger} \mathrm{p}$ value $=0.029$ (Wilcoxon test); ${ }^{\dagger} \mathrm{NS},{ }^{\int \jmath} \mathrm{p}$ value $=0.005$ (Mann- Whitney $\mathrm{U}$ test).

\section{Discussion}

The Cardiovascular Health Awareness Program (CHAP) is a community-based, patient-centred and multidisciplinary cardiovascular disease prevention program with the ultimate goal of improving participants' cardiovascular health. Components of this program include awareness of individuals about their CVD risk factors as well as connection with community programs and resources to support participants in the improvement of their cardiovascular health. CHAP programs have been adapted for different settings and populations [8] [9] [10] [11] [19]. In addition, their efficacy in improving cardiovascular health has been reported [7] [13]. Partenariat Santé is based on CHAP and consists of a free session held in the community by students in various health-sciences programs at Université Laval [15]. This study aimed to obtain a general view of the potential results of the PS program, and more specifically: 1) to explore the characteristics of the adult population participating in the program and the risk factors they targeted to modify; 2) to evaluate one month later the implementation of the action plan elaborated during the motivational interview; and 3) to evaluate the satisfaction of the participants with the PS program.

As expected, there was a significant spread range in participant age, from 19 to 77 years, indicating that PS reaches a diversified population. Based on the blood pressure and waist circumference values obtained during the sessions, a significant percentage of the participants evidenced a profile of increasing cardiovascular risk. The blood pressure values indicate that about $30 \%$ of the participants had systolic values $\geq 140$ and/or diastolic values $\geq 90 \mathrm{mmHg}$. These results are similar to those previously reported in a similar population of individuals registered on a waiting list for a family physician (mean age of 58.1 years, $58 \%$ of women) and for which a third of participants had blood pressure $\geq$ $140 / 90 \mathrm{mmHg}$ [10]. Moreover, $40 \%$ of the participants presented a waist circumference associated with a higher risk profile [20]. This indicates that individuals attending PS sessions could profit from this program to improve their cardiovascular profiles.

Participants identified physical inactivity and eating behaviours as the most important cardiovascular risk factors to be addressed. Accordingly, action plans predominantly focused on modifying these two risk factors. This observation is consistent with a report showing that physical inactivity and eating behaviours (specifically, inadequate intake of fruit and vegetables) were the predominant risk factors identified by Canadians [3]. This information will be helpful in en- 
suring sufficient training of volunteers who carry out the motivational interview during PS sessions.

The majority of participants implemented their action plans (68.3\%). According to theories of social psychology, motivation is the most important determinant of behavior. Individuals with a positive motivation are likely to adopt the behavior. Thus, the enhanced motivation that can be achieved with the motivational interview is of importance. In our study, we observed that the participants who implemented their action plan had a tendency to have a higher motivation at baseline and at the one-month follow-up, their intention was even higher than at the baseline. Moreover, the motivation of the participants that failed in implementing their action plan presented a decrease in their motivation one month later. In fact, the literature points that planning is regarded as highly valuable in the process of health behaviour change. It bridges the gap between behavioural intentions and health-related behaviours, enhancing the enactment of these behaviours [21].

Additionally, literature regarding motivational interview shows that intervention effectiveness appears to increase with contact time [22] [23]. In a systematic review on effectiveness of motivational interviewing for health change in primary care settings, the authors suggest that when only one session is held, the duration may need to be longer than a typical primary care consultation time (e.g., >30 minutes) and studies that included only one face-to-face session have demonstrated their efficacy when combined with one follow-up phone call [22]. This is of particular importance since PS program consists of only one face-to-face brief session lasting approximately 15 minutes. It is important to mention that studies reporting favorable effects of $\mathrm{CHAP}$ programs on objective cardiovascular outcomes include sessions longer in duration and/or in frequency [7] [12] [13]. The addition of a follow-up phone call could be a feasible and inexpensive intervention to optimize the efficacy of PS program.

Satisfaction with an intervention is a very important point to estimate the feasibility and potential of acceptability of the intervention. Our results point to the high level of satisfaction since $75 \%$ of the participants agreed that PS session was useful and most of them (78.3\%) would recommend PS to friends.

The results of the present study will be useful for improving the PS program in the future. First, the analysis of the action plans indicates heterogeneity in their formulation, most of them targeting health outcomes and not exactly the behaviors to change. More than aiming to "improve health" or "lose weight", it is important that the action plan target behaviors to change e.g., "to do an activity of at least 30 minutes twice a week". Training of volunteers on the SMART tool and its systematic use during PS sessions will help participants implement their action plan [24]. Another important point is to add the elaboration of coping plans that refers to the mental simulation of overcoming anticipated barriers to action. Participants with higher levels of coping planning are more likely to report higher levels of the behavior later. Thus, it is suggested to include both kinds of planning in interventions at different stages in health behaviour change 
[21]. Second, the community resources recommended during the session (and available on the PS Web site at http://www.partenariat-sante.com/) were rarely used by participants, despite such resources being an essential component of CHAP programs. The reasons for this low use rate of community resources are unclear and require clarification to optimize their use.

This study has certain limitations. First, assessment of the impact of PS sessions was limited to gathering information from participants. This approach is associated with a social desirability bias that can positively favor the impact of PS program. CHAP programs have previously demonstrated their benefits on objectively measured outcomes such as blood pressure and cardiovascular events [7] [13]. Measures of such outcomes will be helpful in documenting the real impact of PS sessions on cardiovascular health in the future. A second limitation of this study concerns the selection bias due to the fact that, among individuals who participated in PS sessions, those who agreed to take part in our study might have been more motivated to change their lifestyles. Third, PS is an initiative based on the voluntary participation of students in health sciences. As such, they received training on assessing CVD risk and the use of motivational interviewing. In our study, we did not consider characteristics of volunteers in the data analysis (for example, the field of study, years of experience, quality of the action-plan formulation, etc.). Lastly, we did not assess differences in our results based on where the PS sessions were held (e.g. workplace, public spaces). This characterization will be helpful in targeting locations where PS sessions are most useful.

The results of this study are indeed not new in terms of the benefits of an intervention to change health-related behaviours. However, the strength and relevance of this study lie in the fact that it presents a community action strategy adapted to the Quebec context and led by university students in a perspective of interprofessional collaboration. This opens up new perspectives for integrating these actions into university training by preparing students for the deployment of collaborative interprofessional work while already having positive impacts on society.

In conclusion, the assessment of PS sessions during 2019 suggests they increased the awareness of individuals about their cardiovascular risk factors and the adoption of healthy lifestyles. There is a need to initiate a comprehensive longitudinal research program to conduct a more in-depth assessment of the impact of PS program on the cardiovascular health of Québec residents, including the evaluation of objective outcomes of cardiovascular health.

\section{Conflicts of Interest}

The authors declare no conflicts of interest regarding the publication of this paper.

\section{References}

[1] World Health Organization (2017) Cardiovascular Diseases (CVDs). 
https://www.who.int/news-room/fact-sheets/detail/cardiovascular-diseases-(cvds)

[2] Thériault, L. (2010) The Canadian Heart Health Strategy: Risk Factors and Future Cost Implications. The Conference Board of Canada, Vol. 10.

[3] Public Health Agency of Canada (2009) Tracking Heart Disease and Stroke in Canada. https://www.phac-aspc.gc.ca/publicat/2009/cvd-avc/pdf/cvd-avs-2009-eng.pdf

[4] Chambers, L.W., Kaczorowski, J., Dolovich, L., Karwalajtys, T., Hall, H.L., McDonough, B., Hogg, W., Farrell, B., Hendriks, A. and Levitt, C. (2005) A Community-Based Program for Cardiovascular Health Awareness. Canadian Journal of Public Health, 96, 294-298. https://doi.org/10.1007/BF03405169

[5] McMaster University: Cardiovascular Health Awareness Program (CHAP) https://fammedmcmaster.ca/research/research-projects-programs/projects/cardiova scular-health-awareness-program-chap

[6] Agarwal, G., Angeles, R.N., McDonough, B., McLeod, B., Marzanek, F., Pirrie, M. and Dolovich, L. (2015) Development of a Community Health and Wellness Pilot in a Subsidised Seniors' Apartment Building in Hamilton, Ontario: Community Health Awareness Program Delivered by Emergency Medical Services (CHAP-EMS). BMC Research Notes, 8, Article No. 113. https://doi.org/10.1186/s13104-015-1061-8

[7] Kaczorowski, J., Chambers, L.W., Dolovich, L., Paterson, J.M., Karwalajtys, T., Gierman, T., Farrell, B., McDonough, B., Thabane, L., Tu, K., et al. (2011) Improving Cardiovascular Health at Population Level: 39 Community Cluster Randomised Trial of Cardiovascular Health Awareness Program (CHAP). The BMJ, 342, d442. https://doi.org/10.1136/bmj.d442

[8] Agarwal, G., Angeles, R.N., Dolovich, L., Kaczorowski, J., Gaber, J., Guenter, D., Arnuco, F.D., Lam, H.Y., Thabane, L., O'Reilly, D., et al. (2019) The Community Health Assessment Program in the Philippines (CHAP-P) Diabetes Health Promotion Program for Low- to Middle-Income Countries: Study Protocol for a Cluster Randomized Controlled Trial. BMC Public Health, 19, Article No. 682. https://doi.org/10.1186/s12889-019-6974-z

[9] Guenter, D., Angeles, R., Kaczorowski, J., Agarwal, G., Cristobal, F.L., Arciaga, R., Smith, J.F., Kessomboon, P., Jarraya, F., Agbulos, R., et al. (2017) Choosing the Optimal Method of Blood Pressure Measurement for Limited-Resource Rural Communities in the "Community Health Assessment Program-Philippines". The Journal of Clinical Hypertension, 19, 899-903. https://doi.org/10.1111/jch.13028

[10] Kaczorowski, J., Lussier, M.T., Girard, M. and Beaulieu-Carbonneau, A. (2020) Implementation of Modified Cardiovascular Health Awareness Program for Canadian Adults on a Waiting List for a Family Physician. Journal of Primary Care \& Community Health, 11, 1-7. https://doi.org/10.1177/2150132720976484

[11] Pescatello, L.S., Murphy, D., Vollono, J., Lynch, E., Bernene, J. and Costanzo, D. (2001) The Cardiovascular Health Impact of an Incentive Worksite Health Promotion Program. American Journal of Health Promotion, 16, 16-20. https://doi.org/10.4278/0890-1171-16.1.16

[12] Dahrouge, S., Kaczorowski, J., Dolovich, L., Paterson, M., Thabane, L., Tu, K., Younger, J. and Chambers, L. (2018) Long Term Outcomes of Cluster Randomized Trial to Improve Cardiovascular Health at Population Level: The Cardiovascular Health Awareness Program (CHAP). PLoS ONE, 13, e0201802.

https://doi.org/10.1371/journal.pone.0201802

[13] Ye, C., Foster, G., Kaczorowski, J., Chambers, L.W., Angeles, R., Marzanek-Lefebvre, F., Laryea, S., Thabane, L. and Dolovich, L. (2013) The Impact of a Cardiovascular Health Awareness Program (CHAP) on Reducing Blood Pressure: A Prospective 
Cohort Study. BMC Public Health, 13, Article No. 1230.

https://doi.org/10.1186/1471-2458-13-1230

[14] Pennant, M., Davenport, C., Bayliss, S., Greenheld, W., Marshall, T. and Hyde, C. (2010) Community Programs for the Prevention of Cardiovascular Disease: A Systematic Review. American Journal of Epidemiology, 172, 501-516. https://doi.org/10.1093/aje/kwq171

[15] Allard, M., Thibodeau-Gagnon, F.X., Pal-Singh, M., Goffaux, P. and Bergeret, F. (2017) Partenariat Santé: Students in health Care Programs Join Their Efforts to Fight Cardiovascular Disease in a New and Innovative Way in Québec City. University of Toronto Medical Journal, 94, 41-43.

[16] Rabi, D.M., McBrien, K.A., Sapir-Pichhadze, R., Nakhla, M., Ahmed, S.B., Dumanski, S.M., Butalia, S., Leung, A.A., Harris, K.C., Cloutier, L., et al. (2020) Hypertension Canada's 2020 Comprehensive Guidelines for the Prevention, Diagnosis, Risk Assessment, and Treatment of Hypertension in Adults and Children. Canadian Journal of Cardiology, 36, 596-624. https://doi.org/10.1016/j.cjca.2020.02.086

[17] Douketis, J.D., Paradis, G., Keller, H. and Martineau, C. (2005) Canadian Guidelines for Body Weight Classification in Adults: Application in Clinical Practice to Screen for Overweight and Obesity and to Assess Disease Risk. Canadian Medical Association Journal, 172, 995-998. https://doi.org/10.1503/cmaj.045170

[18] Hall, K., Gibbie, T. and Lubman, D.I. (2012) Motivational Interviewing TechniquesFacilitating Behaviour Change in the General Practice Setting. Australian Family Physician, 41, 660-667.

[19] Kaczorowski, J., Chambers, L.W., Karwalajtys, T., Dolovich, L., Farrell, B., McDonough, B., Sebaldt, R., Levitt, C., Hogg, W., Thabane, L., et al. (2008) Cardiovascular Health Awareness Program (CHAP): A Community Cluster-Randomised Trial among Elderly Canadians. Preventive Medicine, 46, 537-544. https://doi.org/10.1016/j.ypmed.2008.02.005

[20] Lemieux, S., Mongeau, L., Paquette, M.C., Laberge, S. and Lachance, B. (2004) Health Canada's New Guidelines for Body Weight Classification in Adults: Challenges and Concerns. Canadian Medical Association Journal, 171, 1361-1363. https://doi.org/10.1503/cmaj.1032012

[21] Sniehotta, F.F., Schwarzer, R., Scholz, U. and Schüz, B. (2005) Action Planning and Coping Planning for Long-Term Lifestyle Change: Theory and Assessment. European Journal of Social Psychology, 35, 565-576. https://doi.org/10.1002/ejsp.258

[22] Morton, K., Beauchamp, M., Prothero, A., Joyce, L., Saunders, L., Spencer-Bowdage, S., Dancy, B. and Pedlar, C. (2015) The Effectiveness of Motivational Interviewing for Health Behaviour Change in Primary Care Settings: A Systematic Review. Health Psychology Review, 9, 205-223. https://doi.org/10.1080/17437199.2014.882006

[23] Burke, B.L., Arkowitz, H. and Menchola, M. (2003) The Efficacy of Motivational Interviewing: A Meta-Analysis of Controlled Clinical Trials. Journal of Consulting and Clinical Psychology, 71, 843-861. https://doi.org/10.1037/0022-006X.71.5.843

[24] Rollnick, S., Miller, W.R. and Butler, C.C. (2008) Motivational Interviewing in Health Care: Helping Patients Change Behavior. Guilford Press, New York, US. 